\title{
Penggunaan Ular Tangga Pintar Sebagai Media Memperbaiki Tanda Dan Gejala Resiko Perilaku Kekekerasan Pada ODGJ Dirumah Sakit Jiwa Grhasia Daerah Istimewa Yogyakarta
}

\author{
Subhannur Rahman', Kellyana Irawati², Yonni Prianto ${ }^{3}$ \\ 'Mahasiswa Magister Keperawatan Peminatan Jiwa Universitas Muhammadiyah Yogyakarta \\ 2Dosen Fakultas Keperawatan dan Ilmu Kesehatan Universitas Muhammadiyah Yogyakarta \\ Perawat Rumah Sakit Jiwa Grhasia Provinsi Daerah Istimewa Yogyakarta \\ Jl. Lingkar Selatan, Tamantirto, Kasihan, Bantul, DI Yogyakarta \\ Telpon: 082149651990 \\ E-mail: subhannur1990@gmail.com
}

DOI: https://doi.org/10.33859/dksm.v10i2.524

\begin{abstract}
Abstrak
Latar belakang: Gangguan jiwa (mental disorder) merupakan salah satu dari empat masalah kesehatan utama yang sangat umum terjadi di berbagai negara dan diperkirakan sekitar $12 \%$ menjadi beban penyakit secara global. Salah satu cara untuk menanggulangi permasahan tersebut dapat dilakukan dengan menggunakan kombinasi antara psikofarmakologi dan nonfarmakologi. Terapi nonfaramakologi yang terbukti efektif untuk mengatasi gejala gangguan jiwa adalah dengan menggunakan terapi aktivitas kelompok dalam bentuk permainan ular tangga pintar.

Tujuan: Memperbaiki tanda dan gejala resiko perilaku kekekerasan pada orang dengan gangguan jiwa di Wisma Arjuna Rumah Sakit Jiwa Grhasia DIY.

Metode: Penelitian ini menggunakan case study dalam bentuk terapi aktivitas kelompok melalui media permainan ular tangga yang sudah dimodifikasi.

Hasil: Hasil penelitian ini secara signifikan menunjukkan bahwa penggunaan ular tangga pintar terhadap tanda dan gejala resiko perilaku kekekerasan pada orang dengan gangguan jiwa mengalami perubahan hasil yang positif.

Kesimpulan: Terapi aktivitas kelompok yang dilakukan di Wisma Arjuna Rumah Sakit Jiwa Grhasia dengan menggunakan media ular tangga pintar efektif dalam menurunkan beberapa tanda dan gejala resiko perilaku kekekerasan pada orang dengan gangguan jiwa.
\end{abstract}

Kata Kunci: Terapi Aktivitas Kelompok, Ular Tangga Pintar, Tanda dan Gejala Perilaku Kekerasan, Orang dengan Gangguan Jiwa. 
Introduction: Mental disorder is one of the four major health problems that are very common in various countries and it is estimated that around $12 \%$ is a burden of disease globally. One way to overcome this problem can be done using a combination of psychopharmacology and nonpharmacologic. Nonpharmacologic therapy that is proven effective for treating symptoms of mental disorders is to use group activity therapy in the form of a smart snake ladder game.

Aims: Improve the signs and symptoms of the risk of violent behavior in people with mental disorders at Wisma Arjuna Grhasia DIY Mental Hospital.

Methods: This study uses a case study in the form of group activity therapy through the modified media of snakes and ladders.

Results: The results of this study significantly indicate that the use of snakes and ladders is smart against the signs and symptoms of the risk of violent behavior in people with mental disorders experiencing positive results.

Conclusions: Therapy of group activities carried out at Wisma Arjuna Grhasia Mental Hospital using smart snake ladder media is effective in reducing some signs and symptoms of the risk of violent behavior in people with mental disorders.

Keywords: Therapy Group Activities, Smart Ladder Snakes, Signs and Symptoms of Violent Behavior, People with Mental Disorders.

\section{Pendahuluan}

Gangguan jiwa (mental disorder) merupakan salah satu dari empat masalah kesehatan utama yang sangat umum terjadi di berbagai negara dan diperkirakan sekitar $12 \%$ menjadi beban penyakit secara global (Vos T dkk, 1990-210). World Health Organisation (WHO, 2013) menegaskan jumlah klien gangguan jiwa di dunia mencapai 450 juta orang, dan paling tidak, ada 1 dari 4 orang di dunia mengalami masalah gangguan jiwa dan diprediksikan akan meningkat menjadi 15\% pada tahun 2020. Berdasarkan data Riset
Kesehatan Dasar prevalensi nasional gangguan jiwa berat seperti gangguan psikosis adalah 1,7 permil 1.000 penduduk. Ini berarti lebih dari 400.000 orang menderita gangguan jiwa berat (Kemenkes RI, 2013). Prevalensi gangguan jiwa terbanyak terdapat di Aceh, Bali, Jawa Tengah, Sulawesi Selatan, dan Yogyakarta yaitu masing-masing 2,7\% dan di Riau sendiri prevalensi gangguan jiwa mencapai $0.9 \%$. Dapat disimpulkan bahwa permasalahan kesehatan jiwa akan terus meningkat dan menimbulkan beban kesehatan yang signifikan. Salah satu cara untuk 
Dinamika Kesehatan Jurnal Kebidanan dan Keperawatan Vol 10 No.2 2019 ( ISSN: 2086-3454 EISSN: 2549-4058)

url: http://ojs.dinamikakesehatan.unism.ac.id DOI: https://doi.org/10.33859/dksm.v10i2

Penggunaan Ular Tangga Pintar Sebagai Media Memperbaiki Tanda Dan Gejala Resiko Perilaku Kekekerasan Pada ODGJ Dirumah Sakit Jiwa Grhasia Daerah Istimewa Yogyakarta

menanggulangi permasahan tersebut dapat dilakukan dengan menggunakan kombinasi antara psikofarmakologi dan nonfarmakologi (Sari FS dkk, 2013). Terapi nonfaramakologi yang terbukti efektif untuk mengatasi gejala gangguan jiwa adalah terapi aktivitas kelompok (TAK). Terapi aktivitas kelompok adalah salah satu jenis terapi modalitas yang dilakukan oleh perawat kepada sekelompok klien yang memiliki permasalahan keperawatan yang sama (Keliat,BA \& Akemat, 2005). Salah satu bentuk terapi aktivitas kelompok yang digunakan dalam proses perawatan pada orang dengan gangguan jiwa adalah dengan menggunakan pendekatan permainan ular tangga. Permainan ular tangga merupakan permainan yang mengutamakan kekompakan dan keuletan yang dimainkan oleh beberapa orang (Astiti, 2017). Media berbasis game seperti ini dapat dibuat melalui adopsi suatu jenis permainan kedalam media pengajaran dengan memodifikasi aturan permainan, bentuk, maupun tampilannya (Marta FN, 2017). Jenis terapi ini mempertimbangan dari segi tujuan dan manfaat, diantaranya mampu menstimulasi fungsi kognitif, bahasa, sosial dan emosional para pemainnya (Sriningsih N, 2008, Rifa I, 2012). Penelitian ini secara umum bertujuan untuk mengetahui penggunaan media ular tangga pintar terhadap perbaikan tanda dan gejala resiko perilaku kekekerasan pada orang dengan gangguan jiwa di Wisma Arjuna Rumah Sakit Jiwa Grhasia DIY.

\section{METODE}

Jenis metode yang akan digunakan adalah case study dengan menggunakan terapi aktivitas kelompok melalui media permainan ular tangga yang sudah dimodifikasi baik dari desain tampilan, teknis atau cara permainan dan bentuk yang akan digunakan. Dalam permainan ini, terapis menggunakan beberapa pendekatan seperti art terapi, humor terapi, play terapi dan rekreasi terapi.

\section{Populasi dan Sampel}

Penelitian ini menggunakan beberapa pasien jiwa yang menjalani rawat inap di Wisma Arjuna RSJ Grhasia dengan masalah 
Dinamika Kesehatan Jurnal Kebidanan dan Keperawatan Vol 10 No.2 2019 ( ISSN: 2086-3454 EISSN: 2549-4058)

url: http://ojs.dinamikakesehatan.unism.ac.id DOI: https://doi.org/10.33859/dksm.v10i2

Penggunaan Ular Tangga Pintar Sebagai Media Memperbaiki Tanda Dan Gejala Resiko Perilaku Kekekerasan Pada ODGJ Dirumah Sakit Jiwa Grhasia Daerah Istimewa Yogyakarta

keperawatan resiko perilaku kekerasan. Jumlah sampel yang digunakan sebanyak 5 orang dengan kriteria sampel tidak amuk, kooperatif dan mendapatkan obat psikotik sesuai dosis.

\section{Waktu dan Tempat kegiatan}

Penelitian ini dilakukan selama 3 hari dari tanggal 15 Januari 2019 sampai dengan 17 Januari 2019. Tempat kegiatan di Wisma Arjuna Rumah Sakit Jiwa Ghrasia DIY.

\section{Teknik Pengumpulan Data}

Teknik pengumpulan data yang digunakan dalam penelitian adalah observasi dan tes. Teknik observasi digunakan untuk mengumpulkan data dari aktivitas pasien selama mengikuti proses kegiatan TAK, sedangkan tes digunakan untuk mengumpulkan data dari hasil sebelum dan sesudah terapi aktivitas kelompok (TAK).

\section{HASIL}

Dalam hal ini akan dijelaskan hasil observasi dan tes yang dilakukan kepada peserta yang mengikuti kegiatan Terapi Aktivitas Kelompok dengan menggunakan permainan ular tangga pintar :
Tabel 1Hasil Observasi Terapi Aktivitas Kelompok (Tanggal 15 Januari 2019)

\begin{tabular}{|c|c|c|c|c|}
\hline \multirow{2}{*}{ Sampel } & \multicolumn{3}{|c|}{$\begin{array}{c}\text { Aspek yang dinilai dari Non } \\
\text { Verbal } \\
\end{array}$} & \multirow{2}{*}{ Hari } \\
\hline & $\begin{array}{c}\text { Ekspresi } \\
\text { Wajah }\end{array}$ & $\begin{array}{c}\text { Kontak } \\
\text { Mata }\end{array}$ & $\begin{array}{l}\text { Bahasa } \\
\text { Tubuh }\end{array}$ & \\
\hline Pasien 1 & Tegang & $\begin{array}{c}\text { Ada } \\
\text { kontak } \\
\text { mata }\end{array}$ & $\begin{array}{l}\text { Tidak } \\
\text { gelisah }\end{array}$ & \\
\hline Pasien 2 & Tegang & $\begin{array}{l}\text { Tidak } \\
\text { Ada }\end{array}$ & $\begin{array}{l}\text { Tidak } \\
\text { gelisah }\end{array}$ & \\
\hline Pasien 3 & Tenang & $\begin{array}{c}\text { Ada } \\
\text { kontak } \\
\text { mata }\end{array}$ & $\begin{array}{l}\text { Tidak } \\
\text { gelisah }\end{array}$ & Hari 1 \\
\hline Pasien 4 & Tenang & $\begin{array}{c}\text { Ada } \\
\text { kontak } \\
\text { mata }\end{array}$ & $\begin{array}{l}\text { Tidak } \\
\text { gelisah }\end{array}$ & \\
\hline Pasien 5 & Tenang & $\begin{array}{c}\text { Kontak } \\
\text { mata } \\
\text { Sedikit } \\
\end{array}$ & $\begin{array}{l}\text { Tidak } \\
\text { gelisah }\end{array}$ & \\
\hline
\end{tabular}

Tabel 2 Hasil Observasi Terapi Aktivitas Kelompok (Tanggal 16 Januari 2019)

\begin{tabular}{|c|c|c|c|c|}
\hline \multirow{3}{*}{ Sampel } & \multirow{2}{*}{\multicolumn{3}{|c|}{$\begin{array}{c}\text { Aspek yang dinilai dari Non } \\
\text { Verbal }\end{array}$}} & \multirow{3}{*}{ Hari } \\
\hline & & & & \\
\hline & $\begin{array}{c}\text { Ekspresi } \\
\text { Wajah }\end{array}$ & $\begin{array}{c}\text { Kontak } \\
\text { Mata }\end{array}$ & $\begin{array}{l}\text { Bahasa } \\
\text { Tubuh }\end{array}$ & \\
\hline Pasien 1 & Tegang & $\begin{array}{c}\text { Ada } \\
\text { kontak } \\
\text { mata }\end{array}$ & $\begin{array}{l}\text { Tidak } \\
\text { gelisah }\end{array}$ & \multirow{5}{*}{ Hari 2} \\
\hline Pasien 2 & Tegang & $\begin{array}{c}\text { Tidak } \\
\text { ada }\end{array}$ & $\begin{array}{l}\text { Tidak } \\
\text { gelisah }\end{array}$ & \\
\hline Pasien 3 & Tenang & $\begin{array}{c}\text { Ada } \\
\text { kontak } \\
\text { mata }\end{array}$ & $\begin{array}{l}\text { Tidak } \\
\text { gelisah }\end{array}$ & \\
\hline Pasien 4 & Tenang & $\begin{array}{c}\text { Ada } \\
\text { kontak } \\
\text { mata }\end{array}$ & $\begin{array}{l}\text { Tidak } \\
\text { gelisah }\end{array}$ & \\
\hline Pasien 5 & Tenang & $\begin{array}{c}\text { Kontak } \\
\text { mata } \\
\text { Sedikit }\end{array}$ & $\begin{array}{l}\text { Tidak } \\
\text { gelisah }\end{array}$ & \\
\hline
\end{tabular}

Tabel 3 Hasil Observasi Terapi Aktivitas Kelompok (Tanggal 17 Januari 2019)

\begin{tabular}{|c|c|c|c|c|}
\hline \multirow{3}{*}{ Sampel } & \multirow{2}{*}{\multicolumn{3}{|c|}{ Aspek yang dinilai dari Non }} & \multirow{3}{*}{ Hari } \\
\hline & & & & \\
\hline & $\begin{array}{c}\text { Ekspresi } \\
\text { Wajah }\end{array}$ & $\begin{array}{c}\text { Kontak } \\
\text { Mata }\end{array}$ & $\begin{array}{l}\text { Bahasa } \\
\text { Tubuh }\end{array}$ & \\
\hline Pasien 1 & Tenang & $\begin{array}{c}\text { Ada } \\
\text { kontak } \\
\text { mata }\end{array}$ & $\begin{array}{c}\text { Tidak } \\
\text { gelisah }\end{array}$ & \\
\hline Pasien 2 & Tenang & $\begin{array}{l}\text { Ada } \\
\text { Kontak } \\
\text { Mata }\end{array}$ & $\begin{array}{l}\text { Tidak } \\
\text { gelisah }\end{array}$ & \\
\hline Pasien 3 & Tenang & $\begin{array}{c}\text { Ada } \\
\text { kontak } \\
\text { mata }\end{array}$ & $\begin{array}{l}\text { Tidak } \\
\text { gelisah }\end{array}$ & $\begin{array}{l}\text { Hari } \\
3\end{array}$ \\
\hline Pasien 4 & Tenang & $\begin{array}{c}\text { Ada } \\
\text { kontak } \\
\text { mata }\end{array}$ & $\begin{array}{l}\text { Tidak } \\
\text { gelisah }\end{array}$ & \\
\hline Pasien 5 & Tenang & $\begin{array}{c}\text { Ada } \\
\text { kontak } \\
\text { mata }\end{array}$ & $\begin{array}{l}\text { Tidak } \\
\text { gelisah }\end{array}$ & \\
\hline
\end{tabular}


Dinamika Kesehatan Jurnal Kebidanan dan Keperawatan Vol 10 No.2 2019 ( ISSN: 2086-3454 EISSN: 2549-4058)

url: http://ojs.dinamikakesehatan.unism.ac.id DOI: https://doi.org/10.33859/dksm.v10i2

Penggunaan Ular Tangga Pintar Sebagai Media Memperbaiki Tanda Dan Gejala Resiko Perilaku Kekekerasan Pada ODGJ Dirumah Sakit Jiwa Grhasia Daerah Istimewa Yogyakarta

Evaluasi Tanda \& Gejala Pada Diagnosa Keperawatan Resiko Perilaku Kekerasan

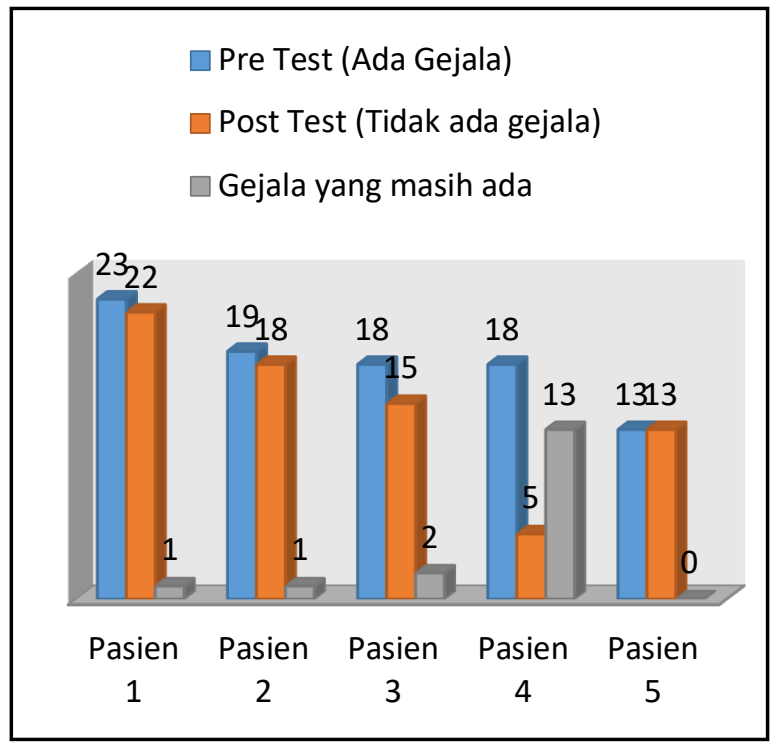

\section{Pembahasan}

Hasil dari case study yang dilakukan menunjukkan bahwa terapi aktivitas kelompok dengan menggunakan media ular tangga pintar melalui pendekatan metode rekreasi terapi, art terapi, humor terapi dan play terapi, efektif dalam memperbaiki tanda dan gejala resiko perilaku kekekerasan pada orang dengan gangguan jiwa.

\section{Terapi Rekreasi}

Terapi rekreasi merupakan salah satu jenis terapi yang bisa memfasilitasi seseorang dalam meningkatkan kesehatan, kemampuan fungsionalnya, kemandirian, dan persepsi kualitas hidup (Lam MH dkk, 2017). Hal ini didukug dengan hasil penelitian Fitzsimmons and Buettner, 2012 yang mengatakan bahwa pelaksanaan terapi jenis ini mampu meningkatkan kualitas hidup orang-orang yang mengalami depresi selama menjalani perawatan dan juga bisa menenangkan individu yang gelisah dan / atau mengingatkan individu yang pasif dengan gangguan kognitif yang biasa menunjukkan perilaku mengganggu (Fitzsimmons MS dkk, 2012).

\section{Art Terapi}

Penggunaan art terapi memiliki manfaat lain seperti meningkatan harga diri, komunikasi dan mengurangi kecemasan, agitasi dan depresi. Hal ini dikarenakan art terapi melibatkan perhatian, kesenangan dan perilaku individu. Selain itu penggunaan media artistic juga mampu sebagai sarana untuk menawarkan cara dalam pasien mengkomunikasikan pengalamannya, perasaan dan kebutuhan mereka yang sulit diungkapkan secara verbal, khususnya pasienpasien yang mengalami masalah ataupun konflik secara emosional maupun masalah spiritual atau eksistensial (K.B dkk, 2014, Chancellor B dkk, 2014). 
Dinamika Kesehatan Jurnal Kebidanan dan Keperawatan Vol 10 No.2 2019 ( ISSN: 2086-3454 EISSN: 2549-4058)

url: http://ojs.dinamikakesehatan.unism.ac.id DOI: https://doi.org/10.33859/dksm.v10i2

Penggunaan Ular Tangga Pintar Sebagai Media Memperbaiki Tanda Dan Gejala Resiko Perilaku Kekekerasan Pada ODGJ Dirumah Sakit Jiwa Grhasia Daerah Istimewa Yogyakarta

\section{Terapi Tawa}

Terapi tawa juga sangat membantu dalam meningkatkan laju pernapasan, aliran darah dan pelepasan adrenalin dalam darah dan akhirnya mengarah kepada perasaan sukacita dan kebahagiaan. Jenis terapi ini merupakan obat yang bersifat murah untuk mencegah dan melawan banyak penyakit Terapi tawa juga mampu meningkatkan asupan oksigen dalam jaringan dengan cara membuat individu menarik napas dalam-dalam. Sehingga dengan tertawa dapat memberikan manfaat baik secara mental maupun kesehatan fisik (Ghodsbin F dkk, 2015). Selain itu tawa telah diindikasikan memiliki beberapa efek fisiologis yang baik, salah satunya membantu individu mengatasi stres dan mengurangi kecemasan (Bast ES dkk, 2014). Humor atau tawa selain memliki efek fisiologis terrnyata juga bisa meningkatkan fungsi kognisi, meningkatkan aktivitas sel pembunuh alami dan menstimulasi sirkulasi didalam tubuh (Bains MD dkk, 2014).

\section{Play Terapi}

Terapi ini merupakan salah satu jenis terapi yang mampu meningkatkan aspek regulasi metakognitif dan perilaku executive function (Esmaili SK dkk, 2017). Terapi jenis ini juga memiliki efektivitas dalam mengurangi agresi pada individu yang agresif, mengurangi gangguan perilaku pada remaja, mengurangi perilaku eksternalisasi dan keterampilan sosial yang lemah, meningkatkan perhatian dan fokus, mengungari gejala impulsif, meningkatkan ketrampilan dalam hubungan interpersonal dan intrapersonal, peningkatan kepercayaan diri dan mengeksternalisasi emosi yang positif dan negatif (Kasmaei SK \& Asghari F, 2017, Ghodousi N dkk, 2017)

\section{Kesimpulan}

Pelaksanaan terapi aktivitas kelompok yang dilakukan dengan menggunakan media ular tangga pintar menjadi salah satu cara yang efektif dalam menurunkan beberapa tanda dan gejala resiko perilaku kekekerasan pada orang dengan gangguan jiwa. 


\section{Saran}

1. Kedepannya peneliti berharap selain instrumen yang sudah digunakan untuk mengukur tanda dan gejala resiko perilaku kekerasan sebelum dan sesudah pemberian TAK menggunakan media ular tangga pintar, ada instrumen tambahan yang bisa digunakan untuk menilai kemampuan pasien dalam mengontrol resiko perilaku kekerasan.

2. Adanya kesediaan tempat yang dibuat secara kondusif dan rekreatif bagi semua peserta yang mengikuti TAK, sehingga pelaksanaan terapi bisa berjalan dengan nyaman dan optimal.

\section{Implikasi Keperawatan}

1. Hasil penelitian ini bisa menjadi salah satu media alternatif dalam membantu memperbaiki tanda dan gejala resiko perilaku kekekerasan pada orang dengan gangguan jiwa

2. Selain itu penelitian ini bisa dijadikan sebagai media baru dalam membantu perawat dalam melaksanakan terapi aktivitas kelompok selanjutnya.

\section{Keterbatasan Penelitian}

Peneliti menyadari didalam pelaksanaan proses penelitian yang dilakukan ada beberapa keterbatasan yang tidak bisa peneliti atasi. Diantaranya waktu penelitian yang terlalu pendek dan lingkungan penelitian yang terkadang tidak kondusif sehingga sedikit banyak akan mengganggu konsentrasi pasien selama mengikuti kegiatan yang dilakukan oleh peneliti.

\section{Ucapan Terimakasih}

Saya mengucapkan terimakasih banyak kepada pihak Rumah Sakit Jiwa Ghrasia DIY beserta tim, klinikal instruktrur dari Rumah Sakit dan Akademik yang telah banyak mendukung, memfasilitasi, membantu dan membimbing penulis dalam menyelesaikan studi kasus ini.

\section{Daftar Pustaka}

Vos T, Flaxman AD, Naghavi M, Lozano R, Michaud C, Ezzati M, et al. Years lived with disability (YLDs) for 1160 sequelae of 289 diseases and injuries 1990-2010: A systematic analysis for the Global Burden of Disease Study 2010. Lancet. 2012;380(9859):216396.

Kemenkes RI. Riset kesehatan dasar tahun 2013. Jakarta: Badan Penelitian dan Pengembangan Kesehatan Kementerian Kesehatan RI; 2013. 
Sari FS, Hakim RL, Kartina I, Nurah- A. Art Drawing Therapy Efektif Menurunkan. KesMaDaSka. 2018;248 (2013).

Keliat, B.A. \& Akemat. Keperawatan Jiwa: Terapi Aktivitas Kelompok, Jakarta: EGD; (2005).

Astiti. Penggunaan Media Permainan Ular Tangga Untuk Meningkatkan Hasil Belajar Siswa Pada Materi Ips Tema Sejarah Peradaban Indonesia Kelas V Sdn Babatan 1/456 Surabaya. JPGSD. 2015; Volume 05(2017):1377.

Farah Nabila Marta, Didi Supriadie RS. Pengaruh Penerapan Model Pembelajaran Kooperatif Tipe Teams Games Tournaments Berbantuan Media Permainan Ular Tangga Terhadap Peningkatan Motivasi Belajar Siswa. Edutcehnologia. 2017;3(2):84-92.

Sriningsih , Nining. Pembelajaran Matematika Terpadu Untuk Anak Usia Dini. Bandung: Pustaka Sebelas; (2008).

Rifa, Iva. Koleksi Games Edukatif di dalam dan Luar Sekolah. Jogjakarta: FlashBooks: (2012).

Lam MH, CHOW B, Cheung SY, Lee KY, Cheung Li WH, Ho E, et al. A Systematic Review of Recreation Therapy for Depression in Older Adults. $\mathrm{J}$ Psychol Psychother [Internet]. 2017;07(02).

Fitzsimmons, MS, ARNP S, Buettner, CTRS, PhD LL. Therapeutic recreation interventions for need-driven dementia compromised behaviors in communitydwelling elders. Am J Recreat Ther [Internet]. 2012;11(1):19-33.

K. B, H. C, T. S, T. O. Arts therapies for anxiety, depression, and quality of life in breast cancer patients: A systematic review and meta-analysis. Evidence- based Complement Altern Med [Internet]. 2014;2014. Available from: http://www.embase.com/search/results? subaction=viewrecord \& from $=$ export\&i $\mathrm{d}=\mathrm{L} 372656217 \% 0$ Ahttp://dx.doi.org/1 $\underline{0.1155 / 2014 / 103297 .}$.

Chancellor B, Duncan A, Chatterjee A. Art therapy for Alzheimer's disease and other dementias. J Alzheimer's Dis. 2014;39(1):1-11.

Ghodsbin F, Ahmadi ZS, Jahanbin I, Sharif F. The Effects of Laughter Therapy on General Health of Elderly People Referring to Jahandidegan Community Center in Shiraz ,. Int J Community Based Nurs Midwifery. 2015;3(1):318.

Bast ES, Berry EM. Laugh Away the Fat? Therapeutic Humor in the Control of Stress-induced Emotional Eating. Rambam Maimonides Med J [Internet]. 2014;5(1):e0007. Available from: http://www.rmmj.org.il/(S(f5bjin00pbr ypdqa5bnwpqmj))/Pages/Article.aspx? manuId=365.

Bains MD GS, Berk DrPH LS, Daher DrPH N, Lohman DSc E, Schwab PhD E, Petrofsky PhD J, et al. The Effect of Humor on Short-term Memory in Older Adults: A New Component for WholePerson Wellness. Adv Mind - Body Med [Internet]. 2014;28(2):16-24.

Esmaili SK, Shafaroodi N, Mehraban AH, Parand A, Zarei M, Akbari-Zardkhaneh S. Effect of play-based therapy on metacognitive and behavioral aspects of executive function: A randomized, controlled, clinical trial on the students with learning disabilities. Basic Clin Neurosci. 2017;8(3):203-12. 
Dinamika Kesehatan Jurnal Kebidanan dan Keperawatan Vol 10 No.2 2019 ( ISSN: 2086-3454 EISSN: 2549-4058)

url: http://ojs.dinamikakesehatan.unism.ac.id DOI: https://doi.org/10.33859/dksm.v10i2

Penggunaan Ular Tangga Pintar Sebagai Media Memperbaiki Tanda Dan Gejala Resiko Perilaku Kekekerasan Pada ODGJ Dirumah Sakit Jiwa Grhasia Daerah Istimewa Yogyakarta

Kasmaei SK, Asghari F. Comparative study of the effects of narrative therapy and play therapy by group approach on inhibiting impulsivity, reducing aggression and increasing interpersonal relations. Middle East J Fam Med [Internet]. 2017;15(4):24-33. Available from: http://search.ebscohost.com/login.aspx ?direct $=$ true $\& \mathrm{db}=\mathrm{a} 9 \mathrm{~h} \& \mathrm{AN}=123580166$ $\&$ site $=$ ehost-live \&scope $=$ site.

Ghodousi N, Sajedi F, Mirzaie H, Rezasoltani P. The Effectiveness of CognitiveBehavioral Play Therapy on Externalizing Behavior Problems Among Street and Working Children. Iran Rehabil $\mathrm{J}$ [Internet]. 2017;15(4):359-66. Available from: http://irj.uswr.ac.ir/article-1-693en.html. 